AperTO - Archivio Istituzionale Open Access dell'Università di Torino

\title{
Asparagine in plums detected by CEST-MRI
}

\section{This is the author's manuscript}

Original Citation:

Availability:

This version is available http://hdl.handle.net/2318/152982

since 2016-10-17T09:44:49Z

Published version:

DOI:10.1016/j.foodchem.2014.07.041

Terms of use:

Open Access

Anyone can freely access the full text of works made available as "Open Access". Works made available under a Creative Commons license can be used according to the terms and conditions of said license. Use of all other works requires consent of the right holder (author or publisher) if not exempted from copyright protection by the applicable law. 
This Accepted Author Manuscript (AAM) is copyrighted and published by Elsevier. It is posted here by agreement between Elsevier and the University of Turin. Changes resulting from the publishing process - such as editing, corrections, structural formatting, and other quality control mechanisms - may not be reflected in this version of the text. The definitive version of the text was subsequently published in FOOD CHEMISTRY, 169, 2015, 10.1016/j.foodchem.2014.07.041.

You may download, copy and otherwise use the AAM for non-commercial purposes provided that your license is limited by the following restrictions:

(1) You may use this AAM for non-commercial purposes only under the terms of the CC-BY-NC-ND license.

(2) The integrity of the work and identification of the author, copyright owner, and publisher must be preserved in any copy.

(3) You must attribute this AAM in the following format: Creative Commons BY-NC-ND license (http://creativecommons.org/licenses/by-nc-nd/4.0/deed.en), 10.1016/j.foodchem.2014.07.041

The publisher's version is available at:

http://linkinghub.elsevier.com/retrieve/pii/S0308814614010747

When citing, please refer to the published version.

Link to this full text:

http://hdl.handle.net/2318/152982 
Asparagine in plums detected by CEST - MRI

Rachele Podda $^{\mathrm{a}, \mathrm{b}}$, Daniela Delli Castelli ${ }^{\mathrm{a}}$, Giuseppe Digilio ${ }^{\mathrm{a}}$, Maria Lodovica Gullino ${ }^{\mathrm{b}}$ and Silvio Aime $^{\mathrm{a}}$

${ }^{a}$ Department of Molecular Biotechnology and Health Sciences, Molecular Imaging and Preclinical Centers,

8 University of Torino, Torino, Italy

${ }^{\mathrm{b}}$ Center of competence for the innovation in the agro-environmental sector (AGROINNOVA). University of

Torino, Via Leonardo da Vinci, 44, 10095 Grugliasco, Torino, Italy

Highlights

- CEST-MRI technique is applied for the first time in fruits

- $\mathrm{pH}$ in plums can be monitorated during the ripening process

- Saturation transfer of amide protons from Asn can be followed by means of CEST-MRI experiments at low magnetic field.

\section{Abstract:}

Magnetic Resonance Imaging (MRI) relies on the topological distribution of the intense water NMR signal and may be used to report about changes in the internal structures of fruits associated to ripening, storing, pathogen infection. Herein the use of CEST-MRI (Chemical Exchange Saturation Transfer) is introduced to show that in addition to structural information, insights into the presence in the fruits of specific chemicals may be gained, Asparagine is present in plums at relatively high concentration $(\approx 10-20 \mathrm{mM}$ ) and owns two amide protons (at 2.1 and $2.8 \mathrm{ppm}$ down field from water) in slow exchange with water protons. By irradiating the amide resonances with a proper rffield it is possible to transfer saturated magnetization to the "bulk" water signal. The attained change in signal intensity reflects the extent of prototropic exchange between amide and water protons that is modulated by the local $\mathrm{pH}$. 
Magnetic resonance imaging is extensively used because it can provide images of internal structures with a good compromise between spatial and temporal resolution. Its wide range parameters linked to water and nondestructive evaluation of various internal quality factors lead to innovative studies in food chemistry [1]. Preliminary studies applied to fruits were focused on $T_{2}, T_{1}$, diffusion coefficient assessment, for internal quality assessment during storage and ripening process studies [2]. In damaged tissues, a contrast is immediately visible in the MR final image.

In this communication we report preliminary results obtained by applying the emerging procedure named CEST-MRI [3]. It relies on the detection of molecules containing mobile protons in slow exchange with water. Fruits may contain many molecules that respond to this requisite, namely aminoacids, peptides, saccharides. CEST-MRI is an encoding frequency procedure that, in principle, allows selecting the contrasting effect due to a specific molecule as the transfer of saturated magnetization (ST) is associated to the irradiation of the mobile proton absorption of the molecule of interest. As a first proof of concept of this approach the resonance of the amide moiety of asparagine (Asn) have been exploited as this amino-acid is known to occur at relatively high concentration in plums [4]

\section{Results and discussion}

Asparagine contains two water exchangeable amide protons that can be exploited for MRI via the CEST effect. To assess the level of asparagine in plum pulp and to assess whether the pulp contained significant sources of exchangeable protons in addition to those of asparagine, the metabolite profile of plum pulp has been acquired by high resolution ${ }^{1} \mathrm{H}-\mathrm{NMR}$ spectroscopy at $14 \mathrm{~T}$ (corresponding to $600 \mathrm{MHz}$ proton Larmor frequency, Figure 1). The most intense signals in such ${ }^{1} \mathrm{H}-\mathrm{NMR}$ spectrum are due to sugars (contributing to the spectral region 4.2-3.2 ppm and 5.4-5-2 ppm), which are known to be very abundant in plum juice under the form of both monosaccharides, disaccharides (mainly sucrose) and fructo-oligosaccharides (FOS) [5,6]. In addition to the saccharide resonances, the resonance of $\mathrm{Asn}_{\beta}$ (2.96 and $2.86 \mathrm{ppm}$ ) and Asn side chain amide protons $(7.60$ and $6.88 \mathrm{ppm})$ are clearly detectable. No other significant sources of exchangeable amide protons with chemical shifts close to the amide resonances were detected. A concentration of Asn of $17.0 \pm 0.5 \mathrm{mM}$ could be determined by integrating the Asn $\mathrm{H}_{\beta}$ resonances with respect to that of reference $60 \mathrm{mM}$ TSP. The concentration of Asn did not change significantly in plums from harvest up to 14-days ripening time (full ripening). 


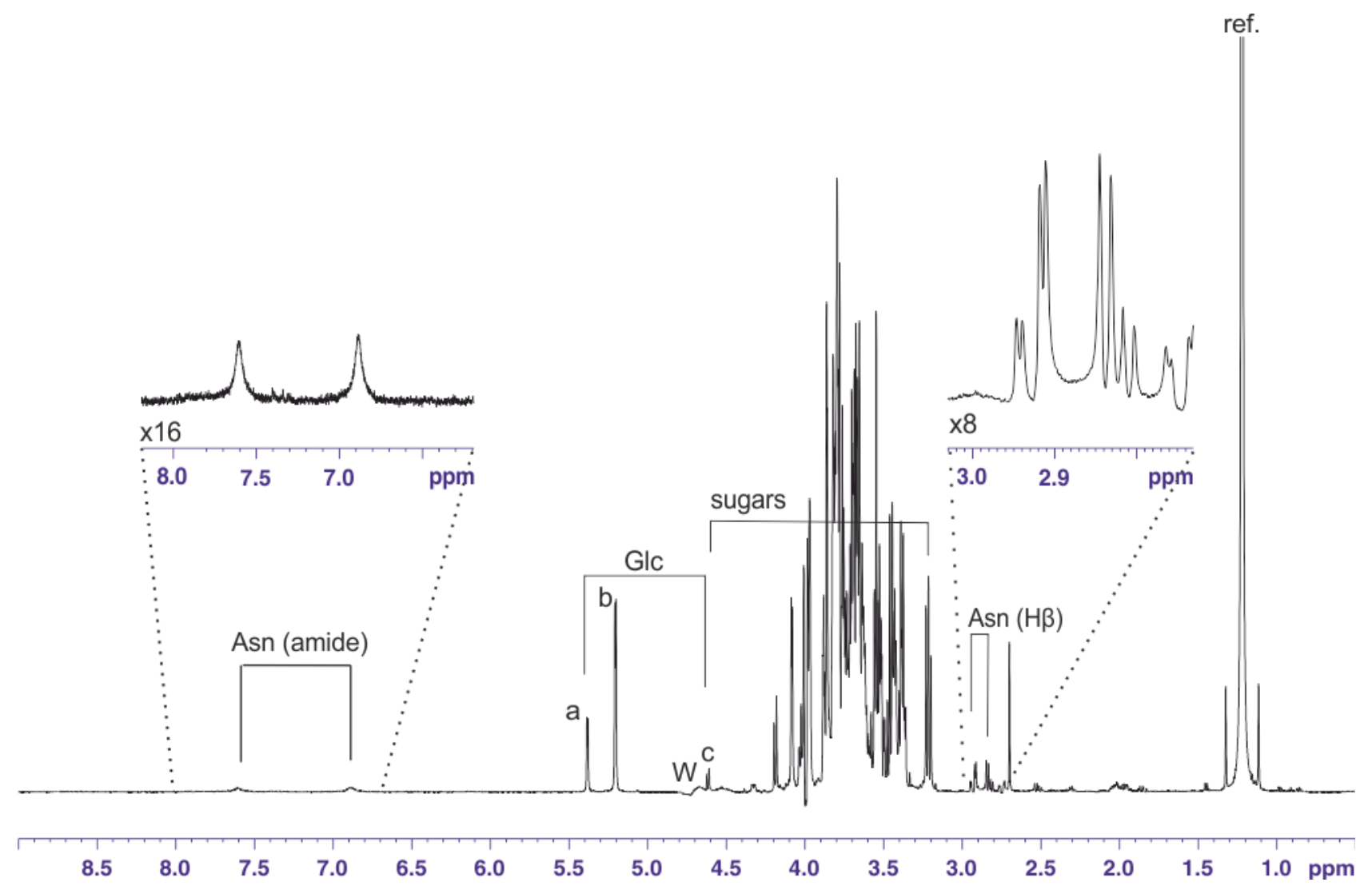

Figure 1. ${ }^{1} \mathrm{H}-\mathrm{NMR}$ spectrum at $600 \mathrm{MHz}$ of plum juice at 7-days post harvest $\left(1: 10\right.$ dilution with $\mathrm{dH}_{2} \mathrm{O}$, $\mathrm{H}_{2} \mathrm{O} / \mathrm{D}_{2} \mathrm{O} 95 / 5 \mathrm{v} / \mathrm{v}, \mathrm{pH} 4.5,25^{\circ} \mathrm{C}$ ). Water suppression was achieved by excitation sculpting with gradients to avoid saturation transfer of exchangeable protons. The resonances of asparagine amide and $\mathrm{H} \beta$ are magnified in the inserts. a: anomeric proton resonance of sucrose/FOS; b: anomeric proton resonance of $\alpha$-D-glucose, $\mathbf{c}$ : anomeric proton resonance of $\beta$-D-glucose; R: reference tert-butanol; w: residual water signal.

Next, CEST-MR images were acquired on a scanner working at a magnetic field of 1T. First, a phantom of six tubes containing $17 \mathrm{mM}$ Asn (i.e. the concentration measured in the plum pulp) and at different $\mathrm{pH}$ values was assessed by CEST-MRI, as it is well-known that the exchange rate of amide protons with bulk water is base-catalyzed and rapidly increases with $\mathrm{pH}$. Therefore, at the magnetic field of $1 \mathrm{~T}$, the $\mathrm{pH}$ dependent modulation of the exchange rate can significantly affect the saturation transfer efficiency. The dependency of $\mathrm{ST}$ on $\mathrm{pH}$ has been assessed within the $\mathrm{pH}$ interval 3.3-5.5, to include $\mathrm{pH}$ conditions of plum pulp juice after harvest $(\mathrm{pH} 3.3$ for the cultivar considered) and at full ripening (pH 4.5). As expected (Figure 2), high ST\% (35\%) can be obtained from the solutions at the more acidic $\mathrm{pH} 3.3$ (irradiation frequency offset at $2.1 \mathrm{ppm}$ from the water resonance), while the CEST effect steadily drops to $10 \%$ at $\mathrm{pH} 5.5$. 


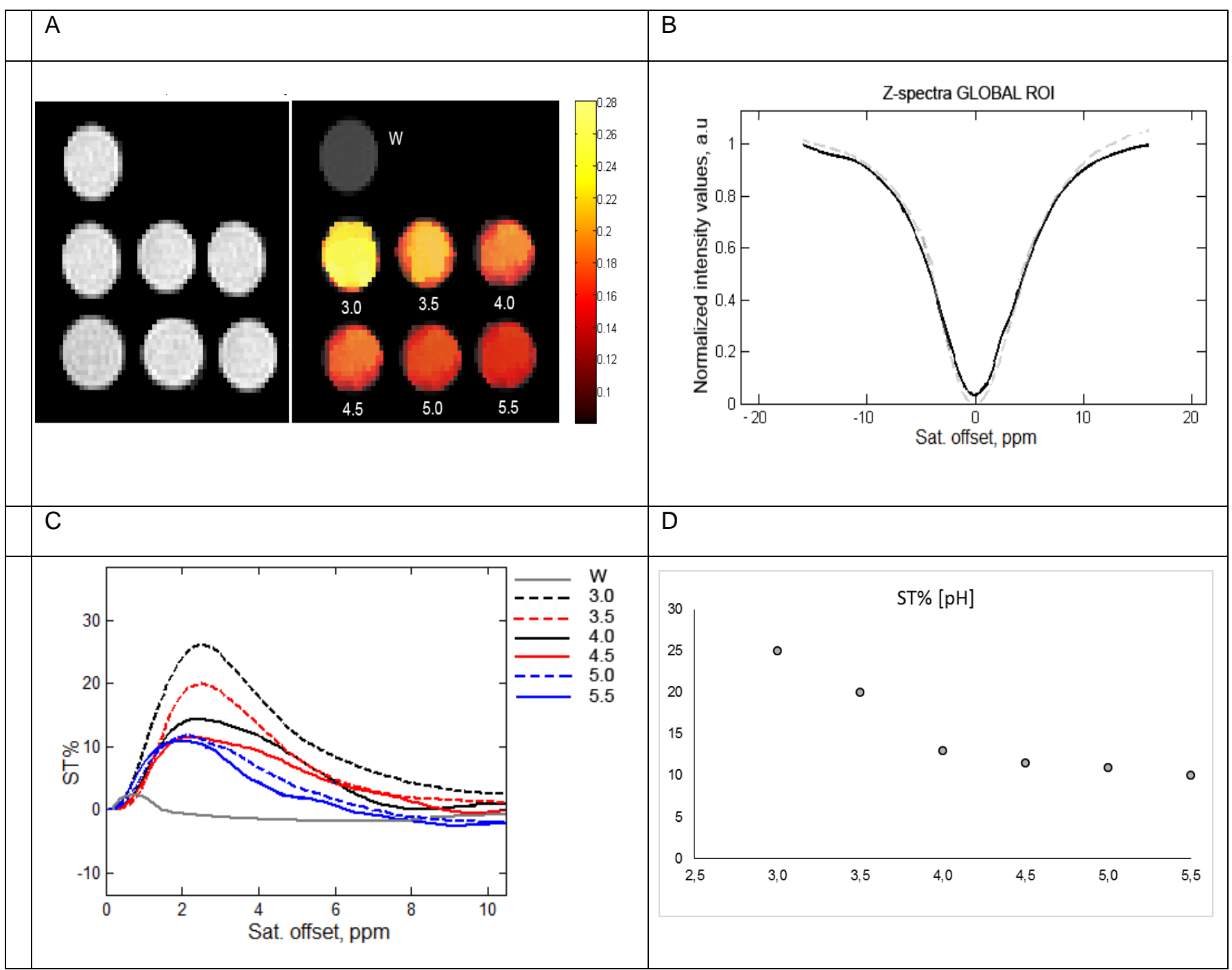

79

80

81

82

83

84

85

86

87

88

89 
Figure 2. CEST-MRI of asparagine solutions at different $\mathrm{pH}(3.3,3.5,4.0,4.5,5.0,5.5)$, 1T. A) CEST-MR images of $17 \mathrm{mM}$ Asn (irradiation offset at $2.1 \mathrm{ppm}$ with respect to the water resonance). Pixels showing ST\% above 10\% (noise threshold) are represented in false color scale, else they are shown in gray B) Z-spectrum of $17 \mathrm{mM} \mathrm{Asn} \mathrm{(pH} \mathrm{3.3),} \mathrm{water} \mathrm{reference} \mathrm{in} \mathrm{gray} \mathrm{line} \mathrm{.} \mathrm{By} \mathrm{increasing}$ $\mathrm{pH}$, the amide protons exchange faster thus approaching the coalescence, resulting in the decrease of saturation transfer efficiency. C) ST\% Asn $17 \mathrm{mM}$ (with water reference, W). D) Plot of ST\% (from images in $\mathrm{B}$ ) versus $\mathrm{pH}$.

91

On this basis, CEST-MR images of the whole plum were acquired (Figure 3). The irradiating rf offset was at $2.1 \mathrm{ppm}$ and the images were acquired at 7 and 14 days after harvest. Conventional $\mathrm{T}_{2}$ weighted MR images were also acquired to visualize the internal structure and texture of the fruits. At day 7 post harvest, a very high ST\% (25\%) was clearly detected all over the fruit. Conversely, at day 14 , the ST\% is reduced to $15 \%$. The reasons for the observed behaviour may rely on different causes, namely changes in Asn concentration, change in $\mathrm{pH}$ or change in $\mathrm{T}_{1}$ of water protons. Through the acquisition of the high resolution ${ }^{1} \mathrm{H}-\mathrm{NMR}$ spectrum and $\mathrm{T} 1$ measurements of the plum's pulp of these samples it assessed that Asn concentration and $\mathrm{T}_{1}$ of water did not change with ripening. Conversly, the $\mathrm{pH}$ increased from 3.3 to 4.7. Thus we conclude that the change in $\mathrm{pH}$ is the main determinant for the observed change in CEST-MR images taken at day 7 and 14 after harvest.

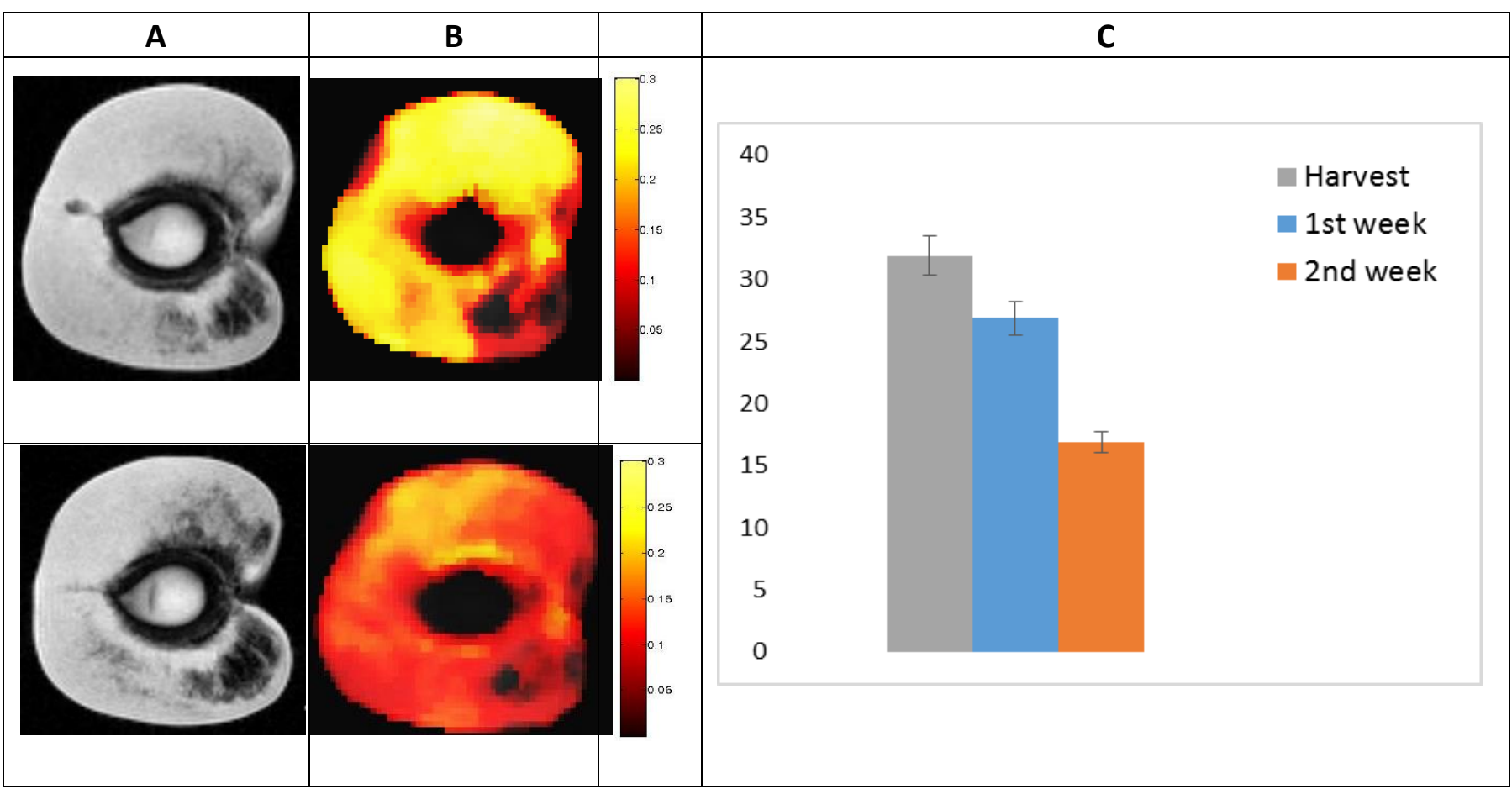


Fig. 3 : plum fruit $T_{1}$-weighted images (A) and ST maps (B) at different chemical shift in thermal scale, from acquired CEST spectra after 7 (left column) and 14 days (right column) post harvest. ST maps were calculated at $\Delta \mathrm{ppm}$ values of amide protons for Asparagine from bulk water (4.7 ppm) .

\section{Conclusions}

This is the first time that CEST-MRI technique has been used to food MRI research area. The

4.1 Fruit imaging

Samples from Prunus domestica cv. TC Sun Angeleno were supplied by Sanifrutta fruit firm, Saluzzo, Piedmont region. Healthy plums with an average diameter of $5 \mathrm{~cm}$ were chosen for experiments. MRI and CEST scans were performed using an ICON Avance M2 (Bruker) with a NdFeBmagnet (Aspect). Operative magnetic field $B_{0}$ was $1 \mathrm{~T}$. $\mathrm{T}_{1^{-}}$and $\mathrm{T}_{2}$-weighted plum images were acquired for preliminar observation before CEST experiments. Fast low angle shot (FLASH) and Rapid acquisition with Refocused echo (RARE) methods was used and for T1- and T2- 
weighted images, respectively. FLASH parameters were set with echo time $5 \mathrm{~s}$, repetition time $184.5 \mathrm{~s}, 4$ averages pulse angle 30 degrees. RARE parameters were set with repetition time $6 \mathrm{~s}$, effective echo time $12.5 \mathrm{~ms}$, rare factor 24 . Geometry parameters were fixed for both sequences as follows: 'field of view $50 \times 50 \mathrm{~mm} /$ slice thickness $2 \mathrm{~mm} /$ matrix $128^{*} 128 \mathrm{px} /$ voxel size $0.3 \mathrm{~mm}^{3}$ '. Temperature was mantained at $6^{\circ} \mathrm{C}$ to prevent consistent tissue destruction and perform scans for 20 days.

All target compounds in this study has small $\Delta \omega$ offsets ranging from about 1 (hydroxyls group of sugars) to $6 \mathrm{ppm}$ (some amine groups). Spillover effect was minimized with low saturation intensities. CEST effects was visualized by means of super-imposed map on a $\mathrm{T}_{1}$ weighted image with no magnetization transfer (MT) pulse. CEST MRI scans were performed using RARE method, which parameters were defined as described above; MT module was active and impulse was a block pulse set in lenght to $3 \mathrm{~s}$ and amplitude $3 \mathrm{uT}$. Other setups were an echo time of $12 \mathrm{~s}$, repetition time $10 \mathrm{~s}$, one number of repetitions, refocusing flip angle $180 \mathrm{deg}$., rare factor 24 and one average. In plane geometry was modified for single axial slices, $4 \mathrm{~mm}$ thickness, FOV $50 \times 50 \mathrm{~mm}$, matrix $64 \times 64 \mathrm{px}$, voxel size $1.2 \mathrm{~mm}^{3}$.

\section{$4.2{ }^{1} \mathrm{H}-\mathrm{NMR}$ spectroscopy.}

All ${ }^{1} \mathrm{H}-\mathrm{NMR}$ spectra were acquired on a BrukerAvance III spectrometer operating at $14.1 \mathrm{~T}$, corresponding to a proton Larmor frequency of $600 \mathrm{MHz}$, equipped with an inverse Z-gradient 5 $\mathrm{mm}$ double resonance inverse probe. The temperature was controlled within $\pm 0.1 \mathrm{~K}$ through the BTO2000 VTU system. ${ }^{1} \mathrm{H}-\mathrm{NMR}$ spectra aimed at assessing the presence of exchangeable protons were carried out by diluting the plump juice $1: 10$ with $\mathrm{dH}_{2} \mathrm{O}$ without $\mathrm{pH}$ adjustment. An aliquot of $540 \mu \mathrm{L}$ of the diluted sample were added with $50 \mu \mathrm{L}$ of $\mathrm{D}_{2} \mathrm{O}$ for field/frequency lock and $1 \mu \mathrm{L}$ of tert-butanol as a secondary chemical shift reference. ${ }^{1} \mathrm{H}-\mathrm{NMR}$ spectra were acquired with a pulse sequence performing water suppression by excitation sculpting with gradients [7] to minimize saturation transfer from water to exchangeable protons (Bruker pulprog zgesgp). Acquisition parameters included 3 s relaxation delay, $64 \mathrm{~K}$ complex data points, $16 \mathrm{ppm}$ spectral window, 128 scans, and $3 \mathrm{~ms}$ selective pulse length for water suppression. To quantify the metabolite levels and to obtain metabolic profiles, the plum juice was diluted 1:10 with $100 \mathrm{mM}$ phosphoric buffer $\mathrm{pH}$ 3.3 (final $\mathrm{pH}$ checked and eventually adjusted to to $3.35 \pm 0.05 \mathrm{pH}$ units). A volume of $540 \mu \mathrm{L}$ juice was added with $60 \mu \mathrm{L}$ of $\mathrm{D}_{2} \mathrm{O}$ containing reference tert-butanol to yield a final concentration of $60 \pm 0.05 \mathrm{mM} .{ }^{1} \mathrm{H}-\mathrm{NMR}$ spectra were acquired with the one-dimensional noesy pulse sequence with pre-irradiation of the water signal for water suppression. Acquisition parameters included $5 \mathrm{~s}$ relaxation delay, 128 scans, 4 dummy scans, 20.5 ppm spectral window, $64 \mathrm{~K}$ complex data points, 
$10 \mathrm{~ms}$ mixing time, and $25 \mathrm{~Hz}$ bandwidth of the water suppression pulse. The levels of asparagines was evaluated by comparing the area of the Asn $\mathrm{H} \beta$ signal to that of reference TSP. Metabolite signals were analyzed by the AMIX 3.9.2 software package implemented with the Bruker BBIOREFCODE 2.0.0 database and the BioMagResBank metabolomics database [8].

\subsection{CEST analysis.}

Raw MRI data were processedby means of custom-made software program implemented in MATLAB (the Mathworks Inc., Natick, MA, USA) [9] .Z-spectra and saturation transfer (ST) maps were corrected by means of interpolation method [10].

\section{Acknowledgements}

This work was partially carried out with the support of the CRC foundation for scientific innovation (Cassa di Risparmio di Cuneo), Cuneo, Italy. One of the authors (RachelePodda) undertook this work under the support of the "Center Of Exellence In Preclinical Imaging (CEIP)', insideBioindustry Park del Canavese, CollerettoGiacosa, Ivrea, Italy.

\section{References}

[1] Mariette F., Collewet G., Davenel A., Lucas T. and Musse M. (2012) Quantitative MRI in Food Science \& Food Engineering. Encyclopedia of Magnetic Resonance.

[2] Hall L.D., Evans S.D. and Nott K.P (1998) Measurement of textural changes of food by MRI relaxometry. Magnetic Resonance Imaging, Vol. 16, 485-492.

[3]. Van Zij1 P. C. M and Yadav N. N. (2011) Chemical exchange saturation transfer (CEST): What is in a name and what isn't? Magnetic Resonance in Medicine. Volume 65, 927-948.

[4] Ogasanović (2007) Amino acids content in the fruit of some plum cultivars and hybrids. VIII International Symposium on Plum and Prune Genetics, Breeding and Pomology, International Society for Horticultural Science. Acta Horticulturae, 734.

[5] Kosmal M., Milala J., Kołodziejczyk K., Markowski J., Zbrzeźniak M., Renard M.G.C. (2013) Dietary fiber and cell wall polysaccharides from plum (Prunus domestica L.) fruit, juice and pomace: Comparison of composition and functional properties for three plum varieties. FoodResearch International, Vol. 54 , 1787-1794.

[6] Cortacero R.S., Segura-Carretero A., Cruces-Blanco C., Hernainz-Bermudez de Castro M., Fernandez-Gutierrez A.(2004) Analysis of carbohydrates in beverages by capillary electrophoresis with precolumnderivatization and UV detection. Food Chemistry, Vol. 87, 471-476. 
213 [7] Wu, P.S.C.; Otting, G. (2005) Rapid pulse length determination in high-resolution NMR. 214 Journal of Magnetic Resonance, Vol. 176, 115-119

[8] Markley JL, Anderson ME, Cui Q, Eghbalnia HR, Lewis IA, Hegeman A, Li J, Schulte C, Sussman M, Westler WM, Ulrich EL, Zolnai Z (2007) New Bioinformatics Resources For Metabolomics. Pac Symp. Biocomput., 157-168.

[9] Chu V., Hamarneh G. (2006): MATLAB-ITK Interface for Medical Image Filtering, Segmentation, and Registration, Proc. of SPIE, Vol. 6144, 61443T-7

[10] J. Stancanello, E. Terreno, D. DelliCastelli, C. Cabella, F. Uggeri and S. Aime 2008: Development and validation of a smoothing-splines-based correction method for improving the analysis of CEST-MR images Contrast Media Mol. Imaging, 3 136-149. 